\title{
Guido C. Currarino, MD, Dec. 17, 1920 - Dec. 20, 2015
}

\author{
Nancy Rollins ${ }^{1} \cdot$ Randolph K. Otto ${ }^{2}$
}

Received: 31 December 2015 / Accepted: 6 January 2016 / Published online: 29 January 2016

(C) Springer-Verlag Berlin Heidelberg 2016

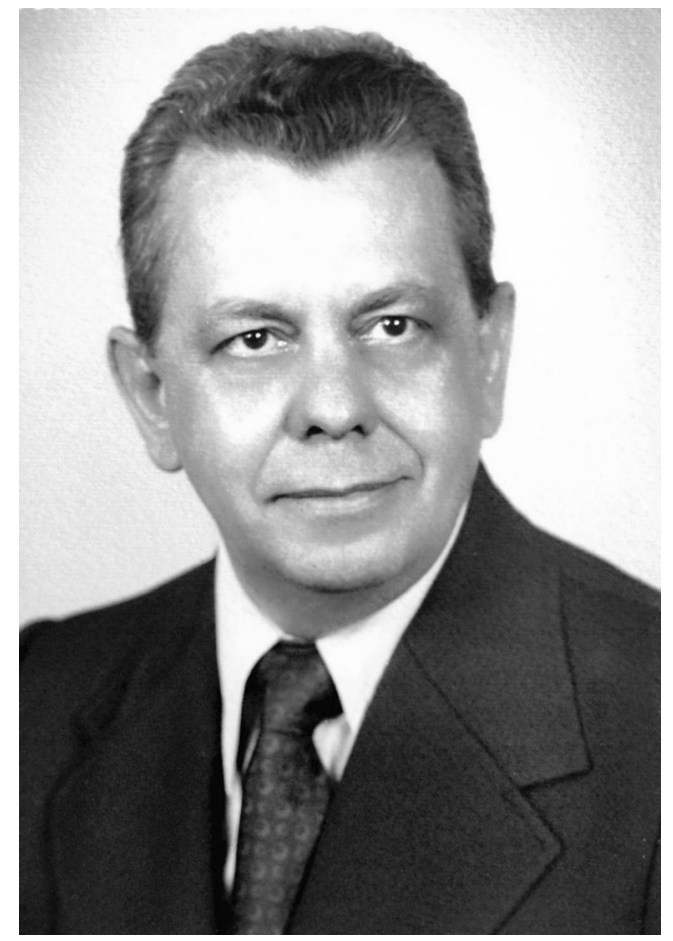

Nancy Rollins

nancy.rollins@childrens.com

1 Department of Radiology, Children's Health System-Texas, University of Texas Southwestern Medical Center, 1935 Medical District Drive, Dallas, TX 75235, USA

2 Department of Radiology, Seattle Children's Hospital, University of Washington School of Medicine, Seattle, WA, USA
Guido Carlo Currarino, a Renaissance man and academician of a by-gone era, passed away Dec. 20, 2015, in Dallas, TX. He was 95 years old.

Dr. Currarino was born in Levanto, Italy, in 1920 and received a classical education that included Greek and Latin; for him, Horace should only be read in Latin. After receiving a medical degree from the University of Genoa in 1945 and pediatric training in Genoa, he then completed a residency in pediatrics. He went on to complete a residency in pediatric radiology at Cincinnati Children's Hospital and a fellowship at Boston Children's Hospital. In 1954 he shared the American Roentgen Ray Society Gold Medal with Dr. Edward Neuhauser for work on hypophosphatasia. He returned to Cincinnati Children's as a staff radiologist from 1955 to 1960 before moving to Cornell University's New York Hospital. In 1965, Dr. Currarino came to Children's Medical Center at the University of Texas Southwestern Medical School in Dallas as a professor of radiology and pediatrics. In 1966 he married Dr. Nellie Luhn, the chief of pediatric anesthesiology at Children's.

Dr. Currarino spent the next 30 years at Children's and UTSW, supplying surgeons with elegant 3-D renderings drawn with wax on sheets of film to guide them in the operating room prior to the era of CT and MRI. He was irascible, humorous, demanding of excellence. He trained countless residents and fellows in the art of plain film diagnosis and scared a few speechless. Morning film interpretation sessions were never mundane or predictable. While many radiographs would pass scrutiny with no substantial commentary, on occasion Dr. Currarino would have a Eureka moment, grabbing the edge of the table while imploring "do you see it??" He would then jump up and off we would go to the radiology library or his office closet. After some dramatic muttering in English mixed with Italian and the tossing aside of books, journals, half-written manuscripts and the skeleton that graced his closet, he would then triumphantly retrieve a bound 
journal from a time long gone and page through until he came across the relevant article, which generally described the entity in question with precise detail. The journal was then placed before the hapless resident with the stern injunction to read. Years later we realized Dr. Currarino routinely ran the alternator in advance of his resident and fellow readout sessions. Even geniuses require some preparation.

He loved fluoroscopy and the teaching of so many subtle ways to optimize the images, instructing us that each image should be so perfect as to be potentially worthy of publication. He always had the grease pencil at the ready to sketch relevant anatomy while explaining the findings and procedural points, with every resident, fellow, technologist and attending leaning in for pointers - never a wasted effort. Dr. Currarino was known for spontaneous visits to the wards, where he could be found, often to the distress of the pediatrician, interrogating a parent or examining a child and thereby providing real-time correlation between the clinical and radiologic findings, functioning as a member of the health care team long before the concept was defined.

After retiring in 1995, he continued to work part-time at the Scottish Rite Hospital for Children in Dallas, where patients, trainees and attending physicians benefitted from his deep expertise in skeletal dysplasias and pediatric orthopedic radiology. A tireless researcher, Dr. Currarino published 122 articles throughout his long career. He was a long-time member of the John Caffey Society and contributed to Caffey's Pediatric X-Ray Diagnosis. He was particularly interested in congenital abnormalities, two of which bear his name: the Currarino syndrome and the Currarino-Silverman syndrome. In 1995 he was awarded the Gold Medal of the Society for Pediatric Radiology for outstanding contributions to the field.

In addition to practicing medicine, Dr. Currarino spoke numerous languages; enjoyed Renaissance art, chamber and opera music, and Latin poetry; and was an outstanding cook, although in the preparatory phase food often found its way to the kitchen ceiling. Dr. Currarino is survived by his wife of 49 years, Nellie Luhn Currarino, his daughter, Rosanne Currarino, his son-in-law, Christopher Warley, and many cousins in Levanto, Italy. He will be remembered by fellow radiologists and clinicians who knew and respected him over his long career. 